\title{
Neonatal hypothermia and associated factors within six hours of delivery in eastern part of Ethiopia: a cross-sectional study
}

Wubet Alebachew Bayih ${ }^{1 *}$, Nega Assefa ${ }^{2}$, Merga Dheresa ${ }^{2}$, Biniam Minuye ${ }^{1}$ and Solomon Demis ${ }^{1}$

\begin{abstract}
Background: Neonatal hypothermia plays a significant role in increasing neonatal death by $80 \%$ for every 1 degree Celsius decrease of body temperature, especially in sub Saharan countries. A global burden of neonatal hypothermia indicated that 53\% of Ethiopian newborns developed hypothermia due to different sociodemographic, behavioral, physiological and birth context related factors. However, the significance of these factors along the spectrum of public health institutions in the study area hasn't been yet studied.

Objective: To assess the prevalence and associated factors of neonatal hypothermia within six hours of delivery at public health institutions of Harar city, Eastern Ethiopia, 2018.

Methods: An institution based cross sectional study was conducted at Harar city after stratified followed by random selection of 3 public health institutions. Every other eligible newborn was included by systematic sampling to yield a sample of 403 newborns and their axillary temperature was measured by a calibrated digital thermometer within six hours of delivery from January 25 to February 19, 2018. A pre-tested anonymous questionnaire and checklist were used. The collected data were cleaned, coded and entered into Epi -data version 4.2 and exported to STATA version 12. Binary logistic regression model was considered and those variables with $P<0.25$ in the bivariable analysis were included in to final model after which statistical significance was declared at $P<0.05$. The goodness of fit was tested by Hosmer-Lemeshow statistic and Omnibus tests. Multi co-linearity was diagnosed using standard error and correlation matrix.
\end{abstract}

Results: The prevalence of neonatal hypothermia in the study area was $66.3 \%$ (95\% Cl: 61.1, 70.5\%). No skin to skin contact ( $A O R=2.87,95 \% \mathrm{Cl}: 1.48,5.57)$, no wearing cap ( $A O R=2.10,95 \% \mathrm{Cl}: 1.17,3.76)$, no warm intra-facility transportation ( $\mathrm{AOR}=3.18,95 \% \mathrm{Cl}: 1.84,5.48)$, born to mothers having obstetric complication ( $\mathrm{AOR}=2.42,95 \% \mathrm{Cl}$ : $1.28,4.57)$, prematurity $(\mathrm{AOR}=3.37,95 \% \mathrm{Cl}: 1.53,7.44)$ and neonatal health problem $(\mathrm{AOR}=4.24,95 \% \mathrm{Cl}: 1.92,9.34)$ were significantly associated with hypothermia.

Conclusion: The prevalence of neonatal hypothermia was relatively high. Therefore, adherence should be made to the thermal care mainly the cost effective ones like wearing cap, skin to skin contact and warm transportation.

Keywords: Hypothermia, Thermo-regulation, Thermal care, Haramaya University

\footnotetext{
* Correspondence: wubetalebachew@gmail.com

'Department of Nursing, College of Health Sciences, Debre Tabor University,

P.O.BOX 272 Debre Tabor, Ethiopia

Full list of author information is available at the end of the article
}

(c) The Author(s). 2019 Open Access This article is distributed under the terms of the Creative Commons Attribution 4.0 International License (http://creativecommons.org/licenses/by/4.0/), which permits unrestricted use, distribution, and reproduction in any medium, provided you give appropriate credit to the original author(s) and the source, provide a link to the Creative Commons license, and indicate if changes were made. The Creative Commons Public Domain Dedication waiver (http://creativecommons.org/publicdomain/zero/1.0/) applies to the data made available in this article, unless otherwise stated. 


\section{Background}

According to World Health Organization, neonatal hypothermia is defined as an abnormal thermal state in which the newborn's body temperature is below $36.5^{\circ} \mathrm{C}$ [1]. It is classified into three different categories based on core temperature of a new-born below $36.5^{\circ} \mathrm{C}$ measured as skin temperature in the axilla: mild hypothermia $\left(36.0^{\circ} \mathrm{C}-36.4{ }^{\circ} \mathrm{C}\right)$, moderate hypothermia $\left(32.0{ }^{\circ} \mathrm{C}-35.9{ }^{\circ} \mathrm{C}\right)$ and severe hypothermia $\left(<32.0^{\circ} \mathrm{C}\right)[1-$ $3]$. For this study, hypothermia was defined as the newborn's body temperature $<36.5^{\circ} \mathrm{C}$.

Immediately after birth, neonates can lose heat through conduction, convection, evaporation and radiation that can cause a reduction of up to $2{ }^{\circ} \mathrm{C}$ of their body temperature within the first 10-20 min of birth [1]. Evaporative loss forms the major route of heat loss in the immediate newborns [1-4]. Therefore, if no action is taken immediately after delivery, the core and skin temperatures of a term neonate can decrease at a rate of approximately $0.1^{\circ} \mathrm{C}$ and $0.3^{\circ} \mathrm{C}$ per minute respectively due to their risky characteristics of large surface area per unit body weight $[5,6]$, decreased subcutaneous fat, greater body water content, immature skin and poorly developed thermoregulatory mechanism [1, 7, 8]. Morbidity and mortality of newborns is uniformly higher among premature and low birth weight newborns as compared to their counter parts [9].

It is a common cause of neonatal morbidity and mortality, even in warmer tropical countries [4] and hence increasingly recognized as a risk factor for new-born survival [5]. Neonatal hypothermia is a worldwide problem with higher prevalence rate among low resource settings. In sub-Saharan countries, it increases neonatal death by $80 \%$ for every 1 degree Celsius decrease of body temperature because it affects all neonatal body systems [3]. It is a major co-morbid of prematurity, severe infections and asphyxia contributing much for the smallest decline in neonatal mortality rate of the Eastern Mediterranean and the African regions [12]. A global burden of neonatal hypothermia indicated that $53 \%$ of newborns in Ethiopia developed hypothermia due to different socio-demographic, physiologic, contextual and behavioral factors $[5,6,13-28]$. However, the significance of these factors within six hours of delivery along the spectrum of public health institutions in the study area hasn't been yet studied.

\section{Methods}

\section{Study area and period}

This study was held in the capital city of Harari regional state, Harar, Eastern Ethiopia which is $525 \mathrm{~km}$ far from Addis Ababa and $48 \mathrm{~km}$ away from Dire Dawa city. The institutional delivery coverage of the region was $79 \%$.There were 6 public health institutions that provide delivery service to the community [29]. The public health institutions in the city were first stratified into strata of specialized Hospital, General Hospital and Health center after which one specialized Hospital namely Hiwot Fana Specialized University Hospital, one General Hospital namely Jugal General Hospital and one Health Center namely Jenniela Health Center were selected randomly from each stratum respectively. The study was conducted from January 25/2018 until February $19 / 2018$.

\section{Study design and participants characteristics}

A descriptive institutional based quantitative cross-sectional study design was conducted. All newborns that were within six hours of their delivery at public health institutions of Harar city together with their mothers were included in the study. However, abandoned newborns were excluded of the study because without maternal involvement it wasn't possible to address most of the variables in the study.

\section{Sample size determination and sampling procedure}

The desired sample was determined by using double population proportion formula with the assumptions of 95\% CI, 5\% margin of error, $80 \%$ power, exposed to unexposed ratio 1:1, 10\% non-response rate and an important variable of the study (skin to skin contact(P1): $75 \%$ and Didn't have skin to skin contact(P2): 87\%) [22]. The final sample size used for the study was 403. By using systematic random sampling, every other eligible live newborn was included into the study.

\section{Measurement and data collection procedure}

Data collection was done by five diploma midwives after they were given one day training of data collection procedure. Data were collected carefully using a pretested and structured interviewer administered questionnaire that contained maternal socio-demographic characteristics and behavioral factors like skin to skin contact, breast feeding, immediate drying, newborn wrapping, cap wearing and warm intra-facility newborn transportation. Moreover, a checklist was used to obtain factors including maternal obstetric complication, neonatal age, birth weight, gestational age at birth, mode of delivery, time of delivery, APGAR score, resuscitation history and neonatal health problem. Axillary temperature of newborns was measured within six hours of delivery for 3 min of duration by using digital thermometer at either delivery or maternity ward.

\section{Data quality control}

The data collection tool was adopted and modified from studies conducted in Ethiopia, Nigeria, Tanzania and Uganda which passed through peer review for its validity 
and published [16-18, 22, 24]. Moreover, a calibrated thermometer (model of MT-101 MT-111) that had measurement accuracy of $\pm 0.1^{\circ} \mathrm{C}$ for the temperature range of $\left(35.5-42.9^{\circ} \mathrm{C}\right)$ and $\pm 0.2^{\circ} \mathrm{C}$ for the temperature range of $\left(32.0-35.5^{\circ} \mathrm{C}\right.$ or above $\left.42^{\circ} \mathrm{C}\right)$ was used [24]. The data collection tool was pretested just two weeks prior to the actual data collection using 20 newborns at the study area based on which some modifications were made to the originally prepared tool. One day training and clear orientation was provided for data collectors and supervisors on the process of data collection. During data collection, data collectors were closely monitored and guided by two BSC nurse supervisors for complete and appropriate collection of the data and reporting to the principal investigator was done on a daily basis. The collected data were double entered into Epidata version 4.2 by two data clerks for validation purpose. The entered data were multivariate analyzed for statistical adjustment of possible confounders.

\section{Operational definition Hypothermia}

A newborn was considered to be hypothermic when its axillary temperature was less than $36.50 \mathrm{C}[1,28]$.

\section{Immediate drying}

A newborn was considered to be immediately dried if and only if its skin was dried on maternal abdomen as soon as delivery prior to cord cutting using dry and prewarmed towel [1].

\section{Neonatal health problem}

Refers to presentation of the neonate with any problem that can trouble its health (congenital malformation, asphyxia, jaundice, respiratory distress, bleeding disorder, meconium aspiration syndrome, etc.) $[1,28]$.

\section{Proper wrapping}

A newborn was considered as properly wrapped if and only if itswhole body including the head and the limbs were wrapped with the use of a pre-warmedand dry towel [1].

\section{Warm intra-facility transportation}

A newborn was considered as warmly transported if and only if it was taken from delivery unit to postnatal or neonatal intensive care unit while being in direct contact with its mother's skin [1].

\section{Data processing and analysis}

The collected data were cleaned manually, coded and entered into Epi data version 4.2 and exported to STATA Version 12 statistical software for data transformation and further analysis. Descriptive statistics like frequencies, proportion, and summary statistics (mean and standard deviation) were used to describe the study population in relation to relevant variables and presented in tables and graphs. Multi-collinearity between the study variables was diagnosed using standard error and correlation matrix. The assumptions for binary logistic regression model were first checked and then bivariate analysis was carried out to identify candidate variables $(p<0.25)$ for multivariate analysis. Using these candidate variables, multivariate analysis was performed to investigate statistically significant independent predictors of hypothermia by adjusting for possible confounders. Finally, variables whose p-value less than 0.05 $(p<0.05)$ from multivariate analysis were declared as statistically significant. Adjusted odds ratio with 95\% CI was considered to identify the strength of association between neonatal hypothermia and its predictors.

\section{Ethical consideration}

Ethical approval was obtained from the Institutional Health Research Ethics Review Committee of College of Health and Medical Sciences of Haramaya University. Official letter was obtained from Haramaya University and submitted to each Hospital and health center to get permission from the respective directors of the institutions. Before conducting the interview, an informed and voluntarily signed written consent (thumb print for those unable to write) was obtained from all the eligible mothers of the newborns. The thermometer was disinfected by $70 \%$ ethyl alcohol disinfectant with a damp cloth after every measure of axillary temperature of the newborn to prevent infection transmission. Hypothermic premature newborns and those with associated problems were helped for referral to neonatal intensive care unit for better management whereas those mildly and moderately hypothermic ones without medical problem were helped by rehabilitative thermal care measures like proper wrapping, frequent breast feeding, skin to skin contact, closing doors and windows etc. Moreover, mothers were advised of thermal care measures on the way to their home and while at their home.

\section{Results}

\section{Socio-demographic factors}

A total of 403 mothers with their neonates were included in the study making $100 \%$ response rate. The mean maternal age was 32 years $(\mathrm{SD}= \pm 5.5)$ and more than half of the mothers $(51.9 \%)$ were in the age group between 20 and 34 years of age. Two hundred twenty nine $(56.8 \%)$ were rural residents. One hundred thirty two respondents $(32.8 \%)$ were unable to read and write and $119(29.5 \%)$ of the respondents were farmers. Furthermore, 258 respondents (64\%) were multiparous (Table 1). 
Table 1 Socio-demographic characteristics of mothers who gave alive birth at public health institutions of Harar city, Eastern Ethiopia, 2018

\begin{tabular}{|c|c|c|c|}
\hline Variables $(\boldsymbol{n}=403)$ & Category & Frequency & Percentage (\%) \\
\hline \multirow[t]{2}{*}{ Residence } & Urban & 174 & 43.2 \\
\hline & Rural & 229 & 56.8 \\
\hline \multirow[t]{6}{*}{ Ethnicity } & Oroomo & 155 & 38.5 \\
\hline & Amhara & 108 & 26.8 \\
\hline & Harari & 58 & 14.4 \\
\hline & Guraghe & 48 & 11.9 \\
\hline & Tigray & 28 & 6.9 \\
\hline & Other & 6 & 1.5 \\
\hline \multirow[t]{4}{*}{ Religion } & Muslim & 178 & 44.2 \\
\hline & Orthodox & 134 & 33.3 \\
\hline & Protestant & 84 & 20.8 \\
\hline & Other & 7 & 1.7 \\
\hline \multirow[t]{3}{*}{ Age } & $<20$ & 12 & 3 \\
\hline & $20-34$ & 208 & 51.6 \\
\hline & $35-49$ & 183 & 45.4 \\
\hline \multirow[t]{4}{*}{ Educational status } & Unable to read and write & 132 & 32.8 \\
\hline & Primary education & 131 & 32.5 \\
\hline & Secondary education & 37 & 9.2 \\
\hline & Diploma and above & 103 & 25.6 \\
\hline \multirow[t]{5}{*}{ Occupational status } & Housewife & 54 & 13.4 \\
\hline & Government employee & 104 & 25.8 \\
\hline & Private employee & 116 & 28.8 \\
\hline & Student & 10 & 2.5 \\
\hline & Farmer & 119 & 29.5 \\
\hline \multirow[t]{2}{*}{ Parity } & Primiparous & 145 & 36 \\
\hline & Multiparous & 258 & 64 \\
\hline
\end{tabular}

\section{Behavioral factors}

Three hundred four (75.4\%) of the newborns were born to mothers who had antenatal care. Almost all of the newborns, 390(96.8\%), were immediately dried. More than half of the newborns, 207 (51.4\%), weren't wrapped properly. Nearly three-fourth of the newborns, 301 (74.7\%) weren't made in contact with their mother's skin. One hundred eighty seven newborns (46.4\%) didn't wear cap. Breastfeeding was initiated within one hour of birth for 287 newborns (71.2\%) and 251(62.3\%) newborns weren't warmly transported from delivery ward to post natal or NICU (Table 2).

\section{Birth context related factors}

It was during the day time that more than half of the newborns, 213(52.9\%), were delivered. Furthermore, $257(63.8 \%)$ of the newborns were delivered through spontaneous vaginal delivery. Most of the newborns were delivered at the specialized University Hospital (Table 3).

\section{Newborn physiology related factors}

The average neonatal age was $3.37 \mathrm{~h}(\mathrm{SD}= \pm 1.72)$ while the average birth weight was $2.94 \mathrm{Kg}(\mathrm{SD}= \pm 0.63)$. Moreover, the average gestational age at birth was almost 38 weeks ( $\mathrm{SD}= \pm 2.52)$ with an average fifth minute APGAR score of $7(\mathrm{SD}= \pm 1.60)$. Male newborns, $202(50.1 \%)$, were almost equal to females, 201(49.9\%). Majority of the newborns, $347(86.1 \%)$, were born single. One hundred four $(25.8 \%)$ of the total newborns were born with health problems. From the overall newborns, one hundred nineteen (29.5\%) were born to mothers who had obstetric complication during pregnancy or labor and/ delivery. From these complications, preeclampsia/ eclampsia disorders comprises the highest percentage, 63(52.9\%), followed by PROM/Sepsis 23(19.3\%), APH, 19(16\%), Obstructed/prolonged labor, 12(10.1\%) and 
Table 2 Behavioral factors of hypothermia among newborns that were born at public health institutions of Harar cty, Eastern Ethiopia, 2018

\begin{tabular}{|c|c|c|c|}
\hline Variable $(n=403)$ & Category & Frequency & Percentage (\%) \\
\hline \multirow[t]{2}{*}{ Had antenatal care } & Yes & 304 & 75.4 \\
\hline & No & 99 & 24.6 \\
\hline \multirow[t]{2}{*}{ Immediate drying } & Yes & 390 & 96.8 \\
\hline & No & 13 & 3.2 \\
\hline \multirow[t]{2}{*}{ Skin to skin contact } & Yes & 102 & 25.3 \\
\hline & No & 301 & 74.7 \\
\hline \multirow[t]{2}{*}{ Proper wrapping } & Yes & 196 & 48.6 \\
\hline & No & 207 & 51.4 \\
\hline \multirow[t]{2}{*}{ Wearing cap } & Yes & 216 & 53.6 \\
\hline & No & 187 & 46.4 \\
\hline \multirow[t]{2}{*}{ Breastfeeding within an hour of birth } & Yes & 287 & 71.2 \\
\hline & No & 116 & 28.8 \\
\hline \multirow[t]{2}{*}{ Warm intra-facility newborn transportation } & Yes & 152 & 37.7 \\
\hline & No & 251 & 62.3 \\
\hline
\end{tabular}

PPH, 2(1.7\%) respectively. Forty (9.9\%) of the newborns were given Cardio-Pulmonary Resuscitation after their birth (Table 4).

\section{Prevalence of neonatal hypothermia}

The prevalence of neonatal hypothermia among newborns who were delivered at public health institutions of Harar city was 267 (66.3\%) [95\% CI: 61.1, 70.5\%)] with mean axillary temperature of 36.24 degree Celsius (SD = \pm 0.69 ) (Fig. 1). Majority of the hypothermic newborns, $150(56.2 \%)$, were mildly hypothermic whereas the rest $117(43.8 \%)$ were moderately hypothermic. The prevalence of hypothermia was highest, 94(90.4\%), among newborns that had health problem(s) (Fig. 2). These problems were respiratory distress syndrome 39(37.5\%), hypoglycemia $33(31.7 \%)$, perinatal asphyxia $25(24.0 \%)$, meconium aspiration syndrome 16(15.4\%), congenital malformation 14(13.5\%), early onset neonatal sepsis

Table 3 Birth context related factors of hypothermia among newborns that were born at public health institutions of Harar city, Eastern Ethiopia, 2018

\begin{tabular}{llll}
\hline Variable $(\mathrm{n}=403)$ & Category & Frequency & Percentage (\%) \\
\hline Delivery time & Day time & 213 & 52.9 \\
& Night time & 190 & 47.1 \\
Delivery mode & SVD & 257 & 63.8 \\
& Instrumental & 34 & 8.4 \\
& $\mathrm{C} / \mathrm{S}$ & 112 & 27.8 \\
Place of delivery & Health Center & 48 & $11.9 \%$ \\
& General Hospital & 105 & $26.1 \%$ \\
& Specialized Hospital & 250 & $62.0 \%$ \\
\hline
\end{tabular}

$12(11.5 \%)$ and jaundice $8(7.7 \%)$. Moreover, hypothermia was found to be more prevalent among preterm newborns $(86.9 \%)$ than term ones $(59.5 \%)$ as shown from the cross tabulation (Table 5). Regarding newborns with perinatal asphyxia, it was found that all the perinatally asphyxiated newborns were hypothermic which may be due to the fact that these newborns can't generate heat as they are in scarce of oxygen (hypoxia) [Fig. 3]. From the scatter plot of their exact body temperature, it can also be easily understood that nearly all the perinatally asphyxiated newborns were moderately hypothermic with a median body temperature of $34.1^{\circ} \mathrm{C}$ and IQR of $2.35^{\circ} \mathrm{C}$ (Table 6).

\section{Predictors of neonatal hypothermia}

Newborns who weren't made in skin to skin contact with their mothers after delivery were 2.9 times more likely to be hypothermic as compared to those who had skin to skin contact $(\mathrm{AOR}=2.87,95 \% \mathrm{CI}$ : $1.48,5.57)$. Newborns who didn't wear cap were 2 times more likely to be hypothermic when compared to those who were dressed with cap (AOR $=2.10,95 \%$ CI: 1.17, 3.76). Newborns who weren't warmly transported from one unit (delivery) to the other (postnatal unit or NICU) were 3.2 times more likely to be hypothermic when compared to those warmly transported ones $(\mathrm{AOR}=3.18,95 \% \mathrm{CI}$ : $1.84,5.48)$. Those newborns who were born to mothers having obstetric complication were 2.4 times more likely to be hypothermic as compared to those born to mothers without any obstetric complication (AOR = 2.42, 95\% CI: 1.28, 4.57). Preterm newborns were 3.4 times more likely to be hypothermic as compared to term ones $(\mathrm{AOR}=3.37,95 \% \mathrm{CI}: 1.53,7.44)$. Moreover, 
Table 4 Physiological factors of hypothermia among newborns that were born at public health institutions of Harar city, Eastern Ethiopia, 2018

\begin{tabular}{|c|c|c|c|}
\hline Variable $(n=403)$ & Category & Frequency & Percentage (\%) \\
\hline \multirow[t]{2}{*}{ Sex } & Male & 202 & 50.1 \\
\hline & Female & 201 & 49.9 \\
\hline \multirow[t]{3}{*}{ Age (hours) } & $(0-2]$ & 142 & 35.2 \\
\hline & $(2-4]$ & 119 & 29.5 \\
\hline & $(4-6]$ & 142 & 35.2 \\
\hline \multirow[t]{2}{*}{ Number of newborns } & Single & 347 & 86.1 \\
\hline & Twin & 56 & 13.9 \\
\hline \multirow[t]{2}{*}{ Birth weight (Kg) } & $<2.5$ (low birth weight) & 81 & 20.1 \\
\hline & $\geq 2.5$ & 322 & 79.9 \\
\hline \multirow[t]{2}{*}{ Gestational age at birth (weeks) } & <37 weeks (preterm) & 99 & 24.6 \\
\hline & $\geq 37$ weeks & 304 & 75.4 \\
\hline \multirow[t]{3}{*}{ APGAR score } & Low & 25 & 6.2 \\
\hline & Moderate & 99 & 24.6 \\
\hline & Normal & 279 & 69.2 \\
\hline \multirow[t]{2}{*}{ Neonatal medical problem } & Yes & 104 & 25.8 \\
\hline & No & 299 & 74.2 \\
\hline \multirow[t]{2}{*}{ Maternal obstetric complication } & Yes & 119 & 29.5 \\
\hline & No & 284 & 70.5 \\
\hline \multirow[t]{2}{*}{ Cardio-pulmonary resuscitation given } & Yes & 40 & 9.9 \\
\hline & No & 363 & 90.1 \\
\hline
\end{tabular}

newborns with health problems were about 4 times more likely to be hypothermic in relative to those who didn't have any problem $(\mathrm{AOR}=4.24,95 \% \mathrm{CI}: 1.92$, 9.34) (Table 7).

\section{Discussion}

The prevalence of neonatal hypothermia among newborns in the study area was $66.3 \%$ which was almost similar with studies conducted in Nigeria (62\%), Addis Ababa (64\%), Bahir Dar, Northwest Ethiopia (67\%) and Gondar,

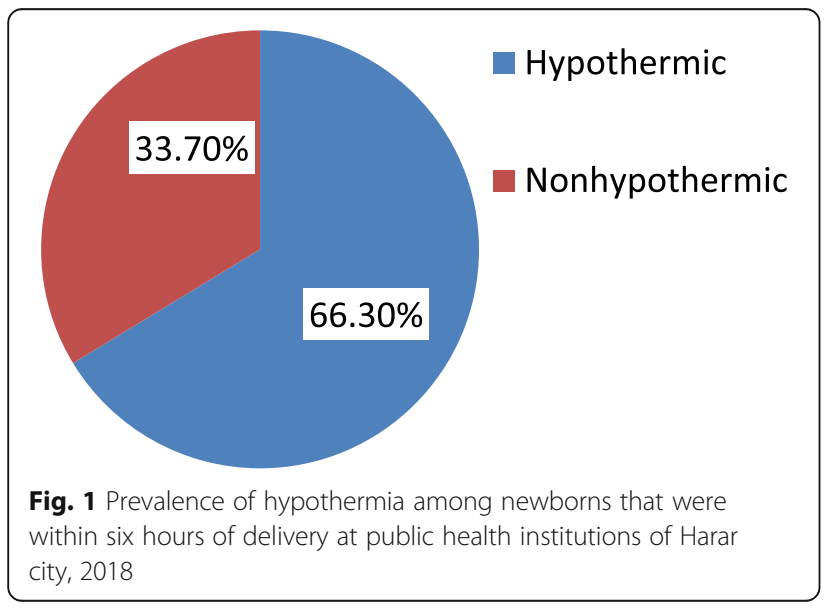

Northwest Ethiopia (69.8\%). This prevalence was lower than studies conducted at Babol, Iran (84.5\%), Zimbabwe (85\%), and Uganda (83\%), but higher than studies conducted in Tehran, Islamic Republic of Iran (53.3\%), South Africa (21\%), Guinea Bissau (8.1\%) and Tanzania (22\%) $[10,16,22,24-26]$. This variation might be due to differences in the temperature measuring instrument, study design, temperature measurement site, sociocultural and ecological factors between the study areas.

This study revealed that newborns with health problems were about 4 times more likely to be hypothermic in relative to those who didn't have. This might be due to the fact that newborns with problems are less likely to breastfeed effectively which makes them to be hypoglycemic that in turn results in hypothermia. It may also be due to another fact that newborns with problems can't take up and utilize oxygen effectively for heat energy production. This finding is almost consistent with the study held at Gondar University Hospital, Northern Ethiopia [16].

Moreover, the study revealed that preterm newborns were 3.4 times more likely to be hypothermic as compared to term ones. The possible reason may be due to the fact that preterm newborns have thinner and more immature skin that increases heat loss through radiation, poor hypothalamic control of their body temperature, lack of efficient neural mechanisms for temperature 


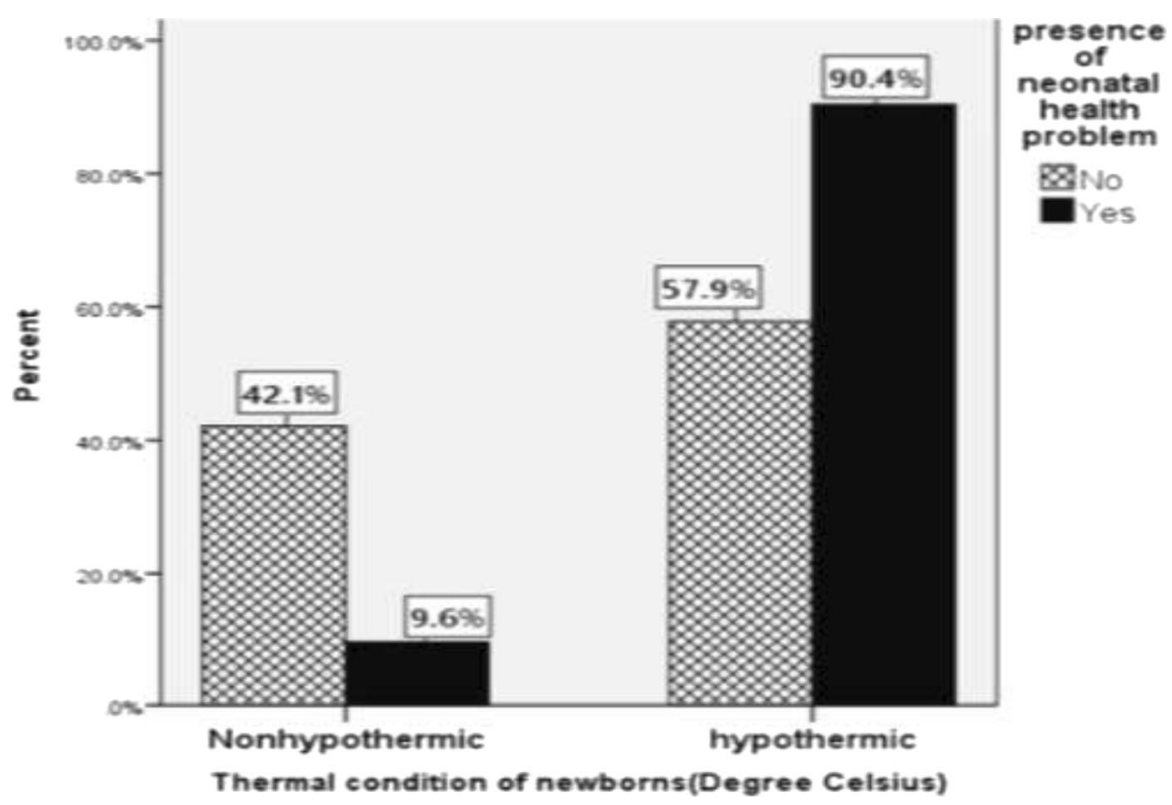

Fig. 2 Comparison of hypothermia with respect to the presence of neonatal health problem among newborns who were delivered at public health institutions of Harar city, Eastern Ethiopia, 2018

control by shivering, decreased glycogen stores, decreased subcutaneous fat for thermal insulation, less brown fat tissue, decreased ability to breastfeed effectively and decreased ability to regulate their body temperature through non-shivering thermogenesis $[1,8$, 11, 23]. This finding was congruent with a study done at Addis Ababa, Ethiopia and Southern Nepal [21, 24].

Those newborns that were born to mothers with obstetric complication were 2.4 times more likely to be hypothermic as compared to those born to mothers without any obstetric complication. This could be due to newborns that were born to mothers with obstetric complication usually have health problems (respiratory distress, perinatal asphyxia, hypoglycemia, etc.). Moreover, newborns of mothers with obstetric complication are often born preterm and/ low birth weight $[8,27]$. This finding is consistent with a Californian cross-sectional data analysis [20].

Newborns who didn't wear cap were 2 times more likely to be hypothermic when compared to those who were dressed with cap and it was comparable with the

Table 5 Cross tabulation of gestational age by thermal status among newborns that were delivered at public health institutions of Harar city, Eastern Ethiopia, 2018

\begin{tabular}{lllll}
\hline & & \multicolumn{2}{l}{ Thermal status } & Total \\
\cline { 3 - 4 } & & Hypothermic & Non hypothermic & \\
\hline Gestational age & Preterm & 86 & 13 & 99 \\
& Term & 181 & 123 & 304 \\
\multirow{2}{*}{ Total } & 267 & 136 & 403 \\
\hline
\end{tabular}

study held at southern Nepal [21]. This could be due to their large head with open fontanels and sutures which contribute to almost $25 \%$ of neonatal heat loss unless dressed with cap [1].

Newborns that weren't made in skin to skin contact with their mothers after delivery were almost 3 times more likely to be hypothermic as compared to those who had skin to skin contact. This may be due to the warm chain principle that there is no transfer of heat from mother to the newborn unless the newborn is in direct contact with its mother's skin. Skin to skin contact is more effective than incubator care for re-warming the newborn. It may also be due to the maternal chest and abdominal movement that stimulates the newborn for enhanced breathing which improves heat generation through oxidative phosphorylation $[1,8]$. This finding is almost consistent with Ethiopian studies conducted at Addis Ababa (AOR $=4.39,95 \% \mathrm{CI}: 2.38,8.11)$ and Gondar, North west Ethiopia (AOR $=2.81,95 \%$ CI: 1.40, 5.66) $[16,24]$. On the other hand, the prevalence of hypothermia among newborns of the study area that weren't made in skin to skin contact $(78.4 \%)$ was lower than a Ugandan study that showed the prevalence of hypothermia being $87 \%$ among newborns without skin to skin contact [22]. This discrepancy might be due to differences in the thermometric site, type of thermometer, maternal awareness of the advantages of skin to skin contact and study period (seasonal variations).

Newborns that weren't warmly transported from delivery unit to postnatal or neonatal intensive care unit were 3.2 times more likely to be hypothermic as compared to those 


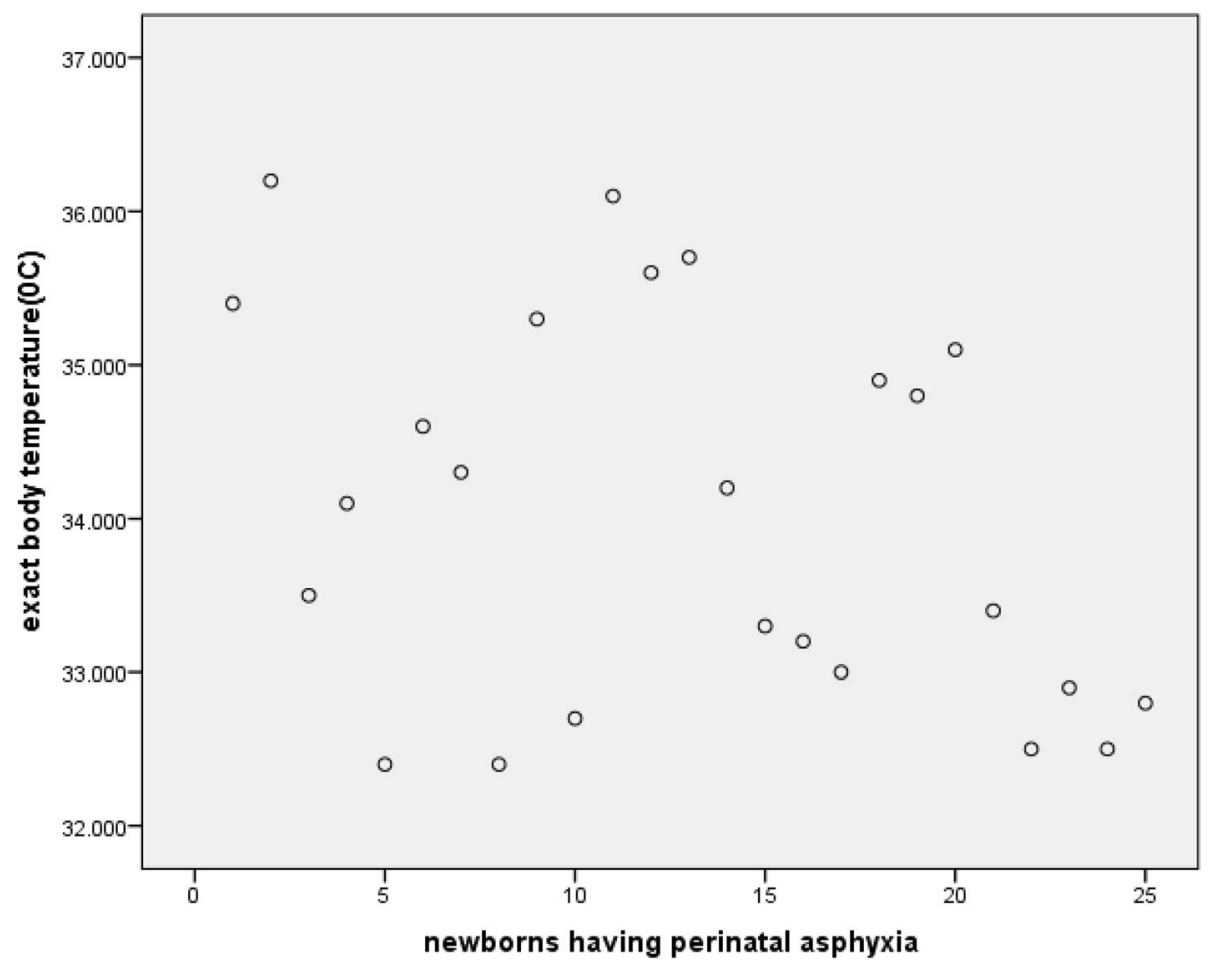

Fig. 3 Scatter plot of the exact body temperature of perinatally asphyxiated newborns who were delivered at public health institutions of Harar city, Eastern Ethiopia, 2018

warmly transported ones. This may be due to the convective and radiant heat loss when newborns aren't kept in contact with their mothers' skin during transportation $[1,8]$.

\section{Limitation of the study}

The study lacks support of qualitative data. As this study was conducted only in the summer season, it couldn't show the significance of seasonal variation for neonatal hypothermia. Moreover, the results may not be representative of the entire newborns in Ethiopia due to a small sample size consideration in this study. Besides, the impact of air temperature of the delivery and postnatal units wasn't considered due to absence of inbuilt thermostat and humidity control in the studied public health institutions. The study also shares drawbacks of a cross-sectional design.

Table 6 Median and IQR of the exact body temperature for perinatally asphyxiated newborns that were delivered at public health institutions of Harar city, Eastern Ethiopia, 2018

\begin{tabular}{lll}
\hline $\mathrm{N}$ & Valid & 25 \\
& Missing & 0 \\
\hline Median & & 34.10 \\
Percentiles & 25 & 32.85 \\
& 50 & 34.10 \\
& 75 & 35.20 \\
\hline
\end{tabular}

* $\mathrm{IQR}=35.20^{\circ} \mathrm{C}-32.85^{\circ} \mathrm{C}=2.35^{\circ} \mathrm{C}$

\section{Conclusion}

The prevalence of neonatal hypothermia in the study area was relatively high. Furthermore, it was found that wearing cap; having skin to skin contact and warm intra-facility newborn transportation were significantly associated with decreased odds of hypothermia whereas neonatal health problems, prematurity and born to mothers with obstetric complication were associated with increased odds of hypothermia.

\section{Based on the study finding, the following public health measures were recommended For maternity and neonatal health care providers}

Neonatal care providers should adhere to the routine practice of warm chain by giving most prioritized attention to newborns with health problems, preterm newborns and those born to mothers with obstetric complication. Mothers should also be oriented of thermal care during their antenatal care, while they are at labor, delivery and postnatal unit.

\section{For the public health institutions}

Every delivery room should have its own thermostat and humidity control so that labor and delivery personnel can adjust the thermostat as needed for any delivery. Delivery room temperature and humidity should be documented at the time of each delivery. Each newborn's 
Table 7 Predictors of neonatal hypothermia among newborns that were born at public health institutions of Harar city, Eastern Ethiopia, 2018

\begin{tabular}{|c|c|c|c|c|}
\hline \multirow[t]{2}{*}{ Variable $(n=403)$} & Hypothermic (267) & Non hypothermic (136) & COR $(95 \% \mathrm{Cl})$ & \multirow[t]{2}{*}{ AOR $(95 \% \mathrm{Cl})$} \\
\hline & $F(\%)$ & \multicolumn{2}{|l|}{$F(\%)$} & \\
\hline \multicolumn{5}{|c|}{ Skin to skin contact } \\
\hline Yes & 31 (30.4\%) & $71(69.6 \%)$ & 1.0 & 1.0 \\
\hline No & $236(78.4 \%)$ & 65 (21.6\%) & $8.32(5.03,13.76)$ & $2.87(1.48,5.57) * * *$ \\
\hline \multicolumn{5}{|l|}{ Wearing cap } \\
\hline Yes & $112(51.9 \%)$ & $104(48.1 \%)$ & 1.0 & 1.0 \\
\hline No & 155 (82.9\%) & $32(17.1 \%)$ & $4.50(2.83,7.16)$ & $2.10(1.17,3.76)^{*}$ \\
\hline \multicolumn{5}{|l|}{ Proper wrapping } \\
\hline Yes & 99 (50.5\%) & 97 (49.5\%) & 1.0 & 1.0 \\
\hline No & $168(81.2 \%)$ & 39 (18.8\%) & $4.22(2.70,6.60)$ & $1.48(0.83,2.64)$ \\
\hline \multicolumn{5}{|l|}{ Early breast feeding } \\
\hline Yes & $179(62.4 \%)$ & $108(37.6 \%)$ & 1.0 & 1.0 \\
\hline No & $88(75.9 \%)$ & $28(24.1 \%)$ & $1.90(1.16,3.09)$ & $1.63(0.88,2.99)$ \\
\hline \multicolumn{5}{|c|}{ Warm transportation } \\
\hline Yes & 69 (45.4\%) & 83 (54.6\%) & 1.0 & 1.0 \\
\hline No & $198(78.9 \%)$ & $53(21.1 \%)$ & $4.49(2.89,6.98)$ & $3.18(1.84,5.48) * * *$ \\
\hline \multicolumn{5}{|c|}{ Obstetric complication } \\
\hline Yes & $100(84 \%)$ & $19(16 \%)$ & $3.69(2.14,6.36)$ & $2.42(1.28,4.57) * *$ \\
\hline No & $167(58.8 \%)$ & $117(41.2 \%)$ & 1.0 & 1.0 \\
\hline \multicolumn{5}{|l|}{ Birth weight (Kg) } \\
\hline$<2.5(\mathrm{LBW})$ & 69 (85.2\%) & $12(14.8 \%)$ & $3.60(1.88,6.92)$ & $1.20(0.51,2.82)$ \\
\hline$\geq 2.5$ (NBW) & $198(61.5 \%)$ & $124(38.5 \%)$ & 1.0 & 1.0 \\
\hline \multicolumn{5}{|c|}{ Gestational age (weeks) } \\
\hline$<37$ (pre-term) & 86 (86.9\%) & $13(13.1 \%)$ & $4.50(2.40,8.41)$ & $3.37(1.53,7.44) * * *$ \\
\hline$\geq 37$ (Term) & $181(59.5 \%)$ & $123(40.5 \%)$ & 1.0 & 1.0 \\
\hline \multicolumn{5}{|c|}{ Neonatal health problem } \\
\hline Yes & 94 (90.4\%) & $10(9.6 \%)$ & $6.85(3.43,13.67)$ & $4.24(1.92,9.34)^{* * *}$ \\
\hline No & $173(57.9 \%)$ & $126(42.1 \%)$ & 1.0 & 1.0 \\
\hline
\end{tabular}

*Significant at $0.013,{ }^{* *}$ significant at 0.007 and ${ }^{* * *}$ significant at $<0.004$

temperature should also be measured and recorded as soon as possible after birth and then every 10-15 min. The postnatal and neonatal intensive care units should be suitably arranged to the delivery unit so that mothers can't be in difficulty of skin to skin contact during intrafacility transportation. The practice of warm chain should also be supervised on a regular basis.

\section{For researchers}

The authors recommend a follow up study supplemented with qualitative data mainly to identify the significance of some factors like seasonal variation.

\section{Abbreviations}

AOR: Adjusted Odds Ratio; APGAR: Appearance, Pulse, Gremace, Activity, Respiration; C/S: Caesarean Section; Cl: Confidence Interval; COR: Crude Odds Ratio; CPR: Cardio Pulmonary Resuscitation; GA: Gestational Age; LBW: Low
Birth Weight; NBW: Normal Birth Weight; NICU: Neonatal Intensive Care Unit; SVD: Spontaneous Vaginal Delivery; WHO: World Health Organization

\section{Acknowledgments}

The author acknowledged directors of the studied public health institutions, data collectors, supervisors and data entry operators. The authors are also deeply indebted to the Institutional Health Research Ethics Review Committee (IHRERC) of Haramaya University for working on the ethical perspectives of the proposal and letting do this study. Last but not least, the respondents deserve sincere thanks for their kind responses.

\section{Consent to publication}

Not applicable.

\section{Authors' contributions}

WA, the corresponding author, worked on designing the study, training and supervising the data collectors, interpreting the result and preparing the manuscript. The co-authors namely NA, MD, BM and SD played their role in analyzing and interpreting the result. Moreover, the co-authors wrote the manuscript. All authors were involved in reading and approving the final manuscript. 


\section{Funding}

This research didn't receive any grant from any funding agency in the public, commercial or not-for-profit sectors.

\section{Availability of data and materials}

Data will be available upon request from the corresponding author.

\section{Ethics approval and consent to participate}

Ethical approval with ethics approval number of HU-CHMS-001 was obtained from Haramaya University, College of Health and Medical Sciences, Institutional Health Research Ethics Review Committee (IHRERC). An informed and voluntarily signed written consent (thumb print for those unable to write) was obtained from all the eligible mothers of the newborns.

\section{Competing interests}

The authors declare that they have no competing interests.

\section{Author details}

'Department of Nursing, College of Health Sciences, Debre Tabor University, P.O.BOX 272 Debre Tabor, Ethiopia. ${ }^{2}$ College of Health and Medical Sciences, Haramaya University, P.O.BOX 235 Harar, Ethiopia.

Received: 4 February 2019 Accepted: 16 July 2019

Published online: 24 July 2019

\section{References}

1. WHO G. Thermal protection of the newborn: a practical guide. Maternal and safe motherhood unit; 2006.

2. Onalo R. Neonatal hypothermia in sub-Saharan Africa :a review Niger. J Clin Pract [serial online]. 2013

3. Onalo.R. Neonatal hypothermia in sub-Saharan Africa : a review Niger J Clin Pract ; 2013;2(16)

4. Lawn JE OD, Adler A, Cousens S. . Europe PMC Funders Group Four million neonatal deaths: 2012:22(5):410-6. Lawn JE, Osrin D, Adler A, Cousens S Europe PMC. Funders Group: Four million neonatal deaths : counting and attribution of cause of death 22(5) 2012; 2012; :410-6.

5. Roya F, Mohammad S, Maryam N. Incidence of neonatal hypothermia at birth in hospitals of Islamic Republic of Iran: a systematic review. J Pediatr. 2014;2(2):2-6.

6. Allen K. Neonatal thermoregulation. Journal of Neonatal Nursing. 2011;2(8): 47-64.

7. Joseph M, Ruth V. Hypothermia in the early neonatal period:follow-up study. Malta Med J. March 2007:19:01

8. CMNRP. Newborn thermoregulation: self - learning module. 2013

9. Mullany L. Neonatal hypothermia in low-resource settings. 2014:4(3):2-20.

10. Zayeri F, Kazemanjad A, Ganjali M, Babae G, Nayeri F. Incidence and risk factors of neonatal hypothermia at refferal hospitals in Tehran, islamic republic of Iran. Eastern Mediteranian journal. 2007;13(6):8-10.

11. Lunze K, Bloom D, Da J, Hamer D. The global burden of neonatal hypothermia: systematic review of a major challenge for newborn survival. BMC 31 January. 2013;11(24):2-20.

12. Mekonnen Y, Tensou B, Telake D, Degefie T, Bekele A. Neonatal mortality in Ethiopia: trends and determinants. BMC. 2013;13:483.

13. World Health Organization. From MDGs, Millennium Development Goals to SDGs, Sustainable Development Goals, 2015

14. Saka K, Balar R, Yirdaz M. Hypothermia in newborn; 2011.

15. EDHS. Key Indicators Report. Central Statistical Agency (CSA) [Ethiopia] and ICF. Addis Ababa, Ethiopia, and Rockville. USA. CSA and ICF: Maryland; 2016. p. 27-8.

16. Seyum T, Ebrahim E. Proportion of neonatal hypothermia and associated factors among new-borns at Gondar University teaching and Refferal hospital, Northwest Ethiopia: a hospital based cross sectional study. Gen Med. 2015;03(04):1-7.

17. Tinuade A, Ogunlesi S, Olusoga B, Ogunfowora D, Folashade A, ABa DMO. Point-of-admission hypothermia among high-risk Nigerian newborns. BMC Pediatr. 2008;8(40).

18. Byaruhanga R, Bergstrom A, Okong P. Neonatal hypothermia in Uganda: prevalence and risk factors. J Trop Pediatr. 2005;51(4):212-5.

19. Delavar M, Akbarianrad Z, Mansouri M, Yahyapour M. Neonatal hypothermia and associated risk factors at baby friendly Hospital in Babol. Iran. 2015:2-5.
20. Miller $\mathrm{S}$, Lee $\mathrm{H}$, Gould J. Hypothermia in very low birth weight infants: distribution, risk factors and outcomes. J Perinatol. 2011;31:49-56.

21. Mullany L, Katz J, Subarna K, LeClerq S. Neonatal hypothermia and associated risk factors among newborns of southern Nepal. BMC Med. 2010; 8(43):15-9.

22. Byaruhan R, Bergstrom A, Okong P. Neonatal hypothermia in Uganda: prevalence and risk factors. Tropical Pediatrics. 2005;51(4).

23. Desta B, Assefa N, Damte T, Hordofa L. Neonatal mortality and its risk factors in eastern Ethiopia: a prospective cohort study in Kersa health and demographic surveillance system (Kersa HDSS). Epidemiol Biostat Public Health. 2016:13(4):2-3.

24. Demissie et al. BMC Pediatrics (2016) 18:263. Neonatal hypothermia and associated factors among newborns admitted to neonatal intensive care unit of governmental hospitals in Addis Ababa, Ethiopia.

25. Thailu, L. \& Pelto, G. 2008. Newborn care practice in Pempa Island (Tanzania) and their implications for newborn health and survival. Modern Child Nutrition 4: 195-209.

26. Tessfaye T, Carin I, Dawed A. Improving neonatal mortality in an Ethiopian referral hospital. Felege Hiwot referral hospital, Bahir Dar, Ethiopia/Bahir Dar University. British Medical Journal ( BMJ). 2015;2(4):36-48.

27. Cunningham, F., Leveno, K., Bloom, S., Sponge, C., Dash, J.\& Hoffman, B. 2014. William's Obsetrics, $24^{\text {th }}$ edition. ISBN: 978-0-07-179894-5. 7 28-1125.

28. Ethiopian Federal Ministry of Health, 2014. Neonatal Intensive Care Unit (NICU) Training Management Protocol.

29. Harari regional health beauro, Eastern Ethiopia. 2018

\section{Publisher's Note}

Springer Nature remains neutral with regard to jurisdictional claims in published maps and institutional affiliations.
Ready to submit your research? Choose BMC and benefit from:

- fast, convenient online submission

- thorough peer review by experienced researchers in your field

- rapid publication on acceptance

- support for research data, including large and complex data types

- gold Open Access which fosters wider collaboration and increased citations

- maximum visibility for your research: over $100 \mathrm{M}$ website views per year

At $\mathrm{BMC}$, research is always in progress.

Learn more biomedcentral.com/submissions 